\title{
An Integrated Model of Material Supplier Selection and Order Allocation Using Fuzzy Extended AHP and Multiobjective Programming
}

\author{
Zhi Li, $^{1}$ W. K. Wong, ${ }^{1}$ and C. K. Kwong ${ }^{2}$ \\ ${ }^{1}$ Institute of Textiles and Clothing, The Hong Kong Polytechnic University, Hunghom, Kowloon, Hong Kong \\ ${ }^{2}$ Department of Industrial and Systems Engineering, The Hong Kong Polytechnic University, Hunghom, Kowloon, Hong Kong \\ Correspondence should be addressed to W. K. Wong; tcwongca@inet.polyu.edu.hk
}

Received 15 October 2012; Accepted 14 December 2012

Academic Editor: Yang Tang

Copyright (C) 2013 Zhi Li et al. This is an open access article distributed under the Creative Commons Attribution License, which permits unrestricted use, distribution, and reproduction in any medium, provided the original work is properly cited.

\begin{abstract}
This paper presents a supplier selection and order allocation (SSOA) model to solve the problem of a multiperiod supplier selection and then order allocation in the environment of short product life cycle and frequent material purchasing, for example, fast fashion environment in apparel industry. At the first stage, with consideration of multiple decision criteria and the fuzziness of the data involved in deciding the preferences of multiple decision variables in supplier selection, the fuzzy extent analytic hierarchy process (FEAHP) is adopted. In the second stage, supplier ranks are inputted into an order allocation model that aims at minimizing the risk of material purchasing and minimizing the total material purchasing costs using a dynamic programming approach, subject to constraints on deterministic customer demand and deterministic supplier capacity. Numerical examples are presented, and computational results are reported.
\end{abstract}

\section{Introduction}

Most manufacturers nowadays face cutthroat competition in the ever-changing market, which leads to establishment of network organizations. Supply chain management offers an integrated decision-making framework to administer such organizations. One of the key functions of supply chain management is the purchasing strategy. For a general producer, purchased items (e.g., raw materials) can account for $60 \%$ of total sales; purchasing shares normally account for $50 \%$ to $90 \%$ of total turnover in an industrial company [1]. Therefore, it is important to manage the process of supplier selection and the strategy of order allocation in order to construct a competitive and effective purchasing function.

Suitable suppliers can give a company a competitive edge and are instrumental to cost reduction and improvement in product quality. Various techniques have been presented to effectively evaluate and select suppliers. For order allocation problem, material purchasing managers firstly determine the optimal materials quantities purchased from each supplier during the purchasing period. An integrated mathematical programming model has then been established to solve supplier selection and order allocation problems based on various assumptions adapting to real-world production.

1.1. Supplier Selection. To deal with supplier selection, many methodologies have been proposed, including categorical methods, case-based reasoning systems [2], statistical models [1], total cost of ownership models [3], mathematical programming, techniques for order preference by similarity to an ideal solution (TOPSISs) [4], and analytic hierarchy processes (AHP) [5]. Among these methods, the analytic hierarchy process (AHPs), first proposed by Saaty (1977), is a popular multiple criteria decision-making technique [6] combining qualitative with quantitative criteria. It is used to rank potential suppliers in a hierarchy system $[7,8]$. However, the AHP frequently fails to adequately accommodate the inherent uncertainty and imprecision associated with mapping decision-makers' perceptions on extracted numbers. It is difficult to respond to preferences of decision-makers by assigning precise numerical values. As a result, the fuzzy 
analytic hierarchy process (FAHP) is proposed $[9,10]$ which incorporates both the fuzzy nets theory and the AHP. To prioritize decision variables, Chan and Kumar [11] proposed the fuzzy extent analytic hierarchy process (FEAHP) which is used in different types of problem [12,13]. In addition, order allocation is another important topic, especially in a multiplesupplier environment.

1.2. Order Allocation. For material purchasing process, after choosing suitable suppliers, order allocation is the next important stage to determine the optimal materials quantities purchased from each supplier, especially in a multiplesupplier environment. Various techniques have been developed to solve the optimal order allocation problem, including linear programming [14], nonlinear programming $[15,16]$, mixed-integer programming [17], and artificial intelligence technique [18-23]. These methods mainly focused on single objective optimization, that is, minimize cost. However, in a real-world supply chain environment, the decision-maker must consider uncertain factors along the supply chain. To reduce the risk, many scholars [24-26] proposed multiobjective optimization models to identify appealing tradeoffs between two or more conflicting objectives involved in the order allocation process. Furthermore, to deal with uncertainty, $\mathrm{Xu}$ and Nozick [27] proposed a two-stage mixedinteger stochastic programming model, which quantified the tradeoff between the risk and cost on the basis of ordering, thus determining optimal supplier sourcing decisions for varying levels of risk tolerance. To solve the multiperiod order allocation problem, dynamic programming has been utilized. Wagner and Whitin [28] employed a dynamic programming solution algorithm to solve a dynamic lot-sizing problem with the objective of minimizing the total cost, under time-varying demands for a single item, inventory holding charges, and setup costs. Basnet and Leung [29] extended the model, which has been proposed by Wagner and Whitin, to a multi-item order allocation problem, with multiple suppliers during a multiperiod planning horizon. Alidaee and Kochenberger [30] solved the single-sink, fixed charge transportation problem by using a dynamic programming method which is able to determine optimal order quantities from a set of potential suppliers to achieve the minimization of cost based on the total materials demands. Li et al. [31] compared periodically purchasing from the spot market with signing a long-term contract with a single supplier with consideration of fluctuant stochastic demand and price. Sawik [32] investigated the problem of multiperiod supplier selection and order allocation in make-to-order environment and proposed a mixed-integer programming approach to incorporate risk that uses conditional value-at-risk via scenario analysis, which is capable of optimizing the dynamic supply portfolio by calculating value-at-risk of cost per part and minimizing expected worst-case cost per part simultaneously.

Based on the aforementioned discussion, few studies $[33,34]$ have investigated material purchasing problems by integrating supplier evaluation and order allocation together. Specifically, research on material purchasing problems with consideration of the features of the fast fashion environment such as imprecise supplier evaluation measure and multiperiod and multiobjective order allocation, has not been reported so far.

The main purpose of this paper is to develop a supplier selection and order allocation (SSOA) model, which is an effective multicriteria decision-making model, to handle material purchasing. Various features in fast fashion environment will be considered, including imprecise supplier evaluation measure, multiple order allocation objectives, varying purchasing prices, supplier capacities, and customer demands in different periods. The SSOA model will combine FEAHP with multiobjective dynamic linear programming technique to generate effective material purchasing solutions.

The rest of this paper is organized as follows. Section 2 presents the mathematical model of optimal order allocation based on supplier rankings. In Section 3, a supply selection (ranking) and order allocation model is developed. In Section 4, experimental results to validate the performance of the proposed model are presented. Conclusions are drawn and future research is suggested in Section 5.

\section{Problem Description}

To meet customers' demands and make a healthy profit, a manufacturer must make an effective sourcing plan based on customers' orders. In the textile industry, manufacturers always need to source common materials (e.g., white fabric) from suppliers over a planning horizon of different periods in order to encourage competition among suppliers and ensure access to a wide variety of goods or services. Therefore, selection of suitable suppliers and an optimal order allocation plan become crucial. This study proposes a model to handle optimal order allocation based on supplier ranking.

The assumptions of this study are as follows.

(1) Each supplier can provide materials for manufacturers, and suppliers have different production capacities.

(2) Manufacturers can get information on each supplier in terms of production capacity and price at the beginning of each planning horizon.

(3) There is no inventory of materials, and manufacturers need to purchase all materials for production.

Let $I=\{1, \ldots, N\}$ represent the set of $N$ suppliers, $J=$ $\{1, \ldots, M\}$ the set of $M$ customer orders, and $T=\{1, \ldots, H\}$ the set of $T$ planning periods. $x_{i t}$ denotes the order quantity from supplier $i . c_{i t}$ denotes the capacity of supplier $i(i \in I)$ in period $t$. $p_{i t}$ denotes the unit price of the material purchased from supplier $i(i \in I)$ in period $t \in T$. $D_{t}$ represents manufacturers' demands for materials based on customers' orders, known ahead of material purchasing. $r_{i}$ represents the relative risk index of supplier $i$, which indicates that a higher value of $r_{i}$ can generate a higher real purchasing risk. Supplier ranking and order allocation investigated in this research can be formulated as follows:

$$
\min E\left(x_{i t}\right)=\min \left(\sum_{t=1}^{T} \sum_{i=1}^{n} p_{i t} \cdot x_{i t}\right),
$$




$$
\begin{array}{cl}
\min & F\left(x_{i t}\right)=\min \left(\sum_{t=1}^{T} \sum_{i=1}^{n} r_{i} \cdot x_{i t}\right), \\
\text { s.t., } \quad\left(0 \leq x_{i t} \leq c_{i t}\right), \quad \forall i, t, \\
\quad \sum_{i=1}^{n} x_{i t}=D_{t}, \quad \forall i .
\end{array}
$$

Formula (1) minimizes the total purchasing costs of materials for all customers' orders. Formula (2) minimizes the total purchasing risks (e.g., delay risk and defect risk). Formula (3) represents that the order quantities are not more than the supplier's maximum capacity in any purchasing periods. Formula (4) requires that the supply must satisfy the demands of manufacturers.

\section{Methodologies for Supplier Selection and Order Allocation}

This paper proposes an effective supplier selection (ranking) and order allocation (SSOA) model based on the FEAHP and dynamic programming (DP). This model comprises an FEAHP-based supplier/criteria ranking process and a DPbased order allocation process (Figure 1).

The details of the SSOA model are described as follows.

3.1. The FEAHP Method. The AHP has been widely used to address multicriteria decision-making problems. It only requires a discrete scale from one to nine. However, human judgement is uncertain of criteria's preferences. The linguistic assessment of human feelings and judgement is vague and cannot be represented reasonably in precise numbers. Hence, triangular fuzzy numbers are used to decide the priority of decision variables. Synthetic extent analysis is used to decide the final priority weights based on triangular fuzzy numbers.

3.1.1. Triangular Fuzzy Numbers and Representation of Preferences. A fuzzy set $[35,36]$ is characterized by a membership function, which assigns to each object a grade of membership ranging from 0 to 1 . The general terms "large", "medium" and "small" are used in fuzzy set to capture a range of numerical values. If $l, m$, and $u$, respectively, denote the smallest possible value, the most promising value, and the largest possible value that describe a fuzzy event, the triangular fuzzy number (TFN) can be denoted as a vector $(l, m, u)$, where $l \leq m \leq u$. When $l=m=u$, it is a nonfuzzy number by convention. The membership function can be defined as

$$
\mu(x \mid M)= \begin{cases}\frac{(x-1)}{(m-1)}, & 1 \leq x \leq m, \\ \frac{(u-x)}{(u-m)}, & m \leq x \leq u \\ 0 & \text { otherwise. }\end{cases}
$$

TFNs $M_{1}, M_{3}, M_{5}, M_{7}$, and $M_{9}$ are used to represent the pairwise comparison of decision variables from "equal" to "absolutely preferred", and TFNs $M_{2}, M_{4}, M_{6}$, and $M_{8}$ represent the middle preference values among them. Figure 2
TABLE 1: Triangular fuzzy numbers.

\begin{tabular}{lcc}
\hline Linguistic variables & $\begin{array}{c}\text { Positive triangular } \\
\text { fuzzy number }\end{array}$ & $\begin{array}{c}\text { Positive reciprocal } \\
\text { triangular fuzzy } \\
\text { number }\end{array}$ \\
\hline Extremely strong & $(8,9,9)$ & $(1 / 9,1 / 9,1 / 8)$ \\
Intermediate & $(7,8,9)$ & $(1 / 9,1 / 8,1 / 7)$ \\
Very strong & $(6,7,8)$ & $(1 / 8,1 / 7,1 / 6)$ \\
Intermediate & $(5,6,7)$ & $(1 / 7,1 / 6,1 / 5)$ \\
Strong & $(4,5,6)$ & $(1 / 6,1 / 5,1 / 4)$ \\
Intermediate & $(3,4,5)$ & $(1 / 5,1 / 4,1 / 3)$ \\
Moderately strong & $(2,3,4)$ & $(1 / 4,1 / 3,1 / 2)$ \\
Intermediate & $(1,2,3)$ & $(1 / 3,1 / 2,1)$ \\
Equally strong & $(1,1,2)$ & $(1 / 2,1,1)$ \\
\hline
\end{tabular}

shows the membership functions of the TFNs, $M_{i}=\left(l_{i}, m_{i}\right.$, $u_{i}$ ), where $i=1,2, \ldots, 9$, and $l_{i}, m_{i}, u_{i}$ are the lower, middle, and upper values of the fuzzy number $M_{i}$, respectively.

3.1.2. Fuzzy Extent Analytic Hierarchy Process (FEAHP). The FEAHP was originally introduced by Chang (1996). Some calculation steps are essential and explained as follows.

Let $X=\left\{x_{1}, x_{2}, x_{3}, \ldots, x_{n}\right\}$ be an object set and $G=$ $\left\{g_{1}, g_{2}, g_{3}, \ldots, g_{n}\right\}$ a goal set. According to Chang's method, each object is taken, and extent analysis of each goal is performed. Therefore, $m$ extent analysis values for each object can be obtained with the following signs: $M_{g_{i}}^{1}, M_{g_{i}}^{2}, \ldots, M_{g_{i}}^{m}$, $i=1,2, \ldots, n$, where $M_{g_{i}}^{j}(j=1,2, \ldots, m)$ are the triangular fuzzy numbers (TFNs).

Step 1. Constructing a hierarchical structure with decision elements, decision-makers are required to make pairwise comparisons between decision alternatives and criteria using a nine-point scale (Table 1). All matrices are developed, and all pairwise comparisons are obtained from each decisionmaker.

Step 2. The fuzzy synthetic extent value with respect to the $i$ th object is defined as:

$$
S_{j}=\sum_{j=1}^{m} M_{g_{i}}^{j} \times\left[\sum_{i=1}^{n} \sum_{j=1}^{m} M_{g_{i}}^{j}\right]^{-1} .
$$

To obtain $\sum_{j=1}^{m} M_{g_{i}}^{j}$, the fuzzy addition operation of $m$ extent analysis values for a particular matrix is performed as

$$
\sum_{j=1}^{m} M_{g_{i}}^{j}=\left(\sum_{j=1}^{m} l_{j}, \sum_{j=1}^{m} m_{j}, \sum_{j=1}^{m} u_{j}\right) .
$$

To obtain $\left[\sum_{i=1}^{n} \sum_{j=1}^{m} M_{g_{i}}^{j}\right]$, the fuzzy addition operation of $M_{g_{i}}^{j}(j=1,2, \ldots, m)$ values is performed as

$$
\sum_{i=1}^{n} \sum_{j=1}^{m} M_{g_{i}}^{j}=\left(\sum_{i=1}^{n} l_{i}, \sum_{i=1}^{n} m_{i}, \sum_{i=1}^{n} u_{i}\right) .
$$




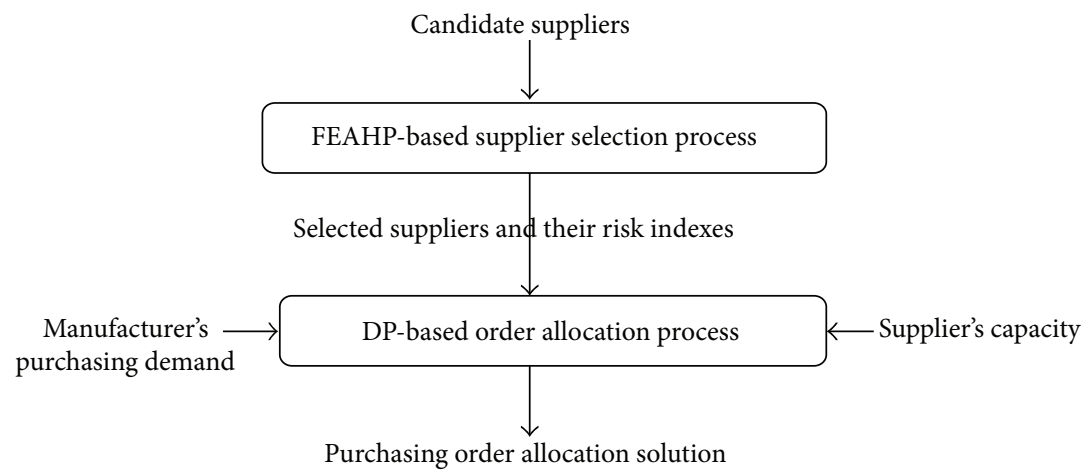

FIGURE 1: The processes of SSOA.

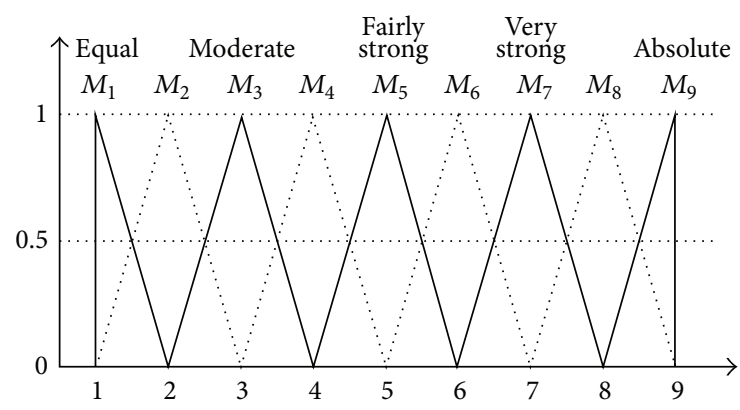

FiguRE 2: The membership functions of triangular fuzzy numbers.

And the inverse of the previous vector is computed as

$$
\left[\sum_{i=1}^{n} \sum_{j=1}^{m} M_{g_{i}}^{j}\right]^{-1}=\left(\frac{1}{\sum_{i=1}^{n} u_{i}}, \frac{1}{\sum_{i=1}^{n} m_{i}}, \frac{1}{\sum_{i=1}^{n} l_{i}}\right) .
$$

Step 3. As $M_{1}=\left(l_{1}, m_{1}, u_{1}\right)$ and $M_{2}=\left(l_{2}, m_{2}, u_{2}\right)$ are two triangular fuzzy numbers, the degree of $M_{2}=\left(l_{2}, m_{2}, u_{2}\right) \geq$ $M_{1}=\left(l_{1}, m_{1}, u_{1}\right)$ possibility of is defined as

$$
V\left(M_{2} \geq M_{1}\right)=\sup _{y \geq x}\left\{\min \left(\mu_{M_{1}}(x), \mu_{M_{2}}(y)\right)\right\}
$$

can be expressed as follows:

$$
\begin{aligned}
V\left(M_{2} \geq M_{1}\right)=\operatorname{hgt}\left(M_{2} \cap M_{1}\right)=\mu_{M_{2}}(d) & \\
= & \begin{cases}1, & \text { if } m_{2} \geq m_{1}, \\
\left|\frac{l_{1}-u_{2}}{\left(m_{2}-u_{2}\right)-\left(m_{1}-l_{1}\right)}\right|, & \text { otherwise. }\end{cases}
\end{aligned}
$$

Equation (11) (Figure 3) indicates that $d$ is the ordinate of the highest intersection point $D$ between $\mu_{M_{1}}$ and $\mu_{M_{2}}$. To compare $M_{1}$ and $M_{2}$, the values of $V\left(M_{2} \geq M_{1}\right)$ and $V\left(M_{1} \geq M_{2}\right)$ are needed.

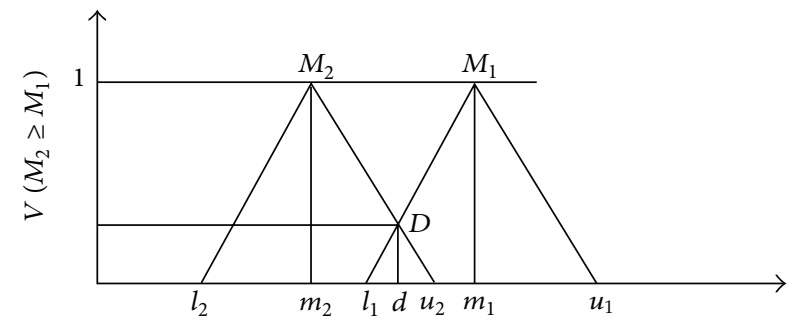

FIgURE 3: The intersection between $M_{1}$ and $M_{2}$.

Step 4 . The degree of possibility that the convex fuzzy number is greater than $k$ convex fuzzy $M_{i}(i=1,2, \ldots, k)$ numbers can be defined by

$$
\begin{aligned}
V(M & \left.\geq M_{1}, M_{2}, \ldots, M_{k}\right) \\
& =V\left[\left(M \geq M_{1}\right) \text { and }\left(M \geq M_{2}\right), \ldots, \text { and }\left(M \geq M_{k}\right)\right] \\
& =\min V\left(M \geq M_{i}\right), \quad(i=1,2,3, \ldots, k) .
\end{aligned}
$$

Assume that $d\left(A_{i}\right)=\min V\left(S_{i} \geq S_{k}\right)$ for $k=1,2, \ldots, n$; $k \neq 1$. Then, the weight vector is given by

$$
W^{\prime}=\left(d^{\prime}\left(A_{1}\right), d^{\prime}\left(A_{2}\right), \ldots, d^{\prime}\left(A_{n}\right)\right)^{\tau},
$$

where $A_{i}(i=1,2,3, \ldots, n)$ are $n$ elements.

Step 5. Via normalization, the normalized weight vectors are

$$
W=\left(d\left(A_{1}\right), d\left(A_{2}\right), \ldots, d\left(A_{n}\right)\right)^{\tau},
$$

where $W$ is a nonfuzzy number.

The upward composition of these weights (from the lowest to the top level) generates the ranking scores (weights) of elements at the lowest level (i.e., suppliers) in fulfilling the topmost objective (i.e., suppliers ranking).

3.1.3. FEAHP-Based Supplier Ranking. As discussed in the introduction, supplier ranking gives decision-makers an 
effective technique to choose suitable suppliers. In this research, supplier ranking is implemented by the FEAHP method. The procedure is detailed as follows.

Step 1 (define criteria for supplier selection). To define effective criteria for supplier selection, this research collects promising candidate criteria based on existing research results (Dickson 1966; Chan and Kumar [11] 2007), and any additional criteria deemed important for manufacturers are included.

On the basis of the candidate criteria selected, structured interviews are used to evaluate these criteria by three senior specialists, including a senior designer and two purchasing managers denoted by $(R 1),(R 2)$, and $(R 3)$, respectively. To evaluate candidate criteria, the respondents are requested to use the linguistic assessment of human feelings (Table 1). Upon receiving the inputs of the respondents, the criteria are identified and averaged. If there are too many criteria, the pairwise comparison can become a difficult and timeconsuming process. To overcome these problems, the criteria's average value in top 5 is selected. In this paper, the 5 final criteria are (1) overall cost of products $\left(C_{1}\right) ;(2)$ quality of product $\left(C_{2}\right)$; (3) risk factors $\left(C_{3}\right) ;(4)$ a supplier's profile $\left(C_{4}\right) ;(5)$ service performance of a supplier $\left(C_{5}\right)$.

Step 2 (define subcriteria for supplier selection). To evaluate suppliers more precisely, each selected criterion in Step 1 needs to be further represented by several subcriteria. The identification and selection of these subcriteria can be implemented as described in Step 1. If the subcriteria are still obscure, they can be re-represented by sub-subcriteria using the same process.

Step 3 (structure the hierarchical model and each criterion's weight). In this step, the FEAHP hierarchy model is built, and the weight of each supplier selection model is calculated. The developed FEAHP model, based on the identified criteria, subcriteria and subcriteria's subcriteria, has five levels: goals, criteria, subcriteria, subcriteria's subcriteria, and candidates. Figure 4 shows the 5 -level hierarchy for supplier selection. The goal of supplier selection for manufacturers is identified on the first level. The second level (criteria) contains 5 criteria mentioned in Step 1. The third and fourth levels consist of subcriteria and subcriteria's subcriteria (subcriteria's subcriteria are not considered in this paper's numerical experimentation). The lowest level of the hierarchy contains alternatives. That is, different suppliers are evaluated in order to pick the best ones. As shown in Figure 4, different suppliers are used to represent the arbitrary ones which manufacturers wish to evaluate.

The FEAHP model (Figure 4) is generally applicable to any type of supplier selection by manufacturers as it covers many important factors and their related criteria, subcriteria, and subcriteria's subcriteria.

In order to obtain the priority weight of each criterion on each level, a second structure is done in a similar manner as Step 1. The interview consisting of factors on each level of the FEAHP model is used to collect the judgments of pairwise comparisons from all evaluation team members. This judgments is performed using pairwise comparisons, which are elaborated in Section 3.1.1. An example of the pairwise comparison matrix is shown in Table 2.

Step 4 (measure supplier performance and identify supplier priority). After obtaining the priority weight of each criterion and subcriterion, the third structured interview is designed and modified. This interview collects the weights of alternatives to identify the best suppliers.

The priority weight is determined for alternatives in this step. The competitive rivals that are supposed to be suppliers for manufacturers are compared by each subcriteria standard. After finding the local weight of each alternative in subcriteria, the global weight of each alternative in each criterion can be calculated. The evaluation of the global weight of each alternative can be obtained by multiplying the global weights of subcriteria and the local weight of each alternative. Based on the global priority, the weight of each alternative can be evaluated and summarized. An example of FEAHP-based supplier ranking is described in Section 4.1.2.

3.2. Dynamic Programming. As purchasing price is timevarying in the model, the cost objective is judiciously captured by the following dynamic value function:

$$
V_{1, t}=\min _{0 \leq x_{i t} \leq c_{i t}}\left\{\sum_{i=1}^{n} p_{i t} x_{i t}+V_{1, t+1}\left(D_{t}-\sum_{i=1}^{n} x_{i t}\right)\right\},
$$

where stage is decision dates in time periods, $t=1,2, \ldots, T$. The decision variable is the quantities ordered from supplier $i, x_{i t}=0,1, \ldots, c_{i t}$.

To account for both objectives, a distance-to-ideal framework is employed to integrate the risk and cost objective functions, using the optimal values of individual objectives obtained earlier.

To incorporate the ideal values of risk and cost, the sum (weights) of deviations from such ideal values is minimized. Hence, a dynamic value function is derived as follows:

$$
\begin{array}{r}
V_{2, t}=\min _{0 \leq x_{i t} \leq c_{i t}}\left\{w_{c_{1}} \sum_{i=1}^{n} p_{i t} x_{i t}+w_{c_{3}} \sum_{i=1}^{n} \frac{x_{i t}}{w_{i}}\right. \\
\left.+V_{2, t+1}\left(D_{t}-\sum_{i=1}^{n} x_{i t}\right)\right\},
\end{array}
$$

where $V_{2, t}$ is the minimum total weighted deviation. $w_{c_{1}}$ is the cost weight defined by decision-makers using the FEAHP. $w_{\mathcal{c}_{3}}$ is the risk weight defined by decision-makers using the FEAHP.

\section{Numerical Experiments}

To validate the effectiveness of the proposed SSOA model, a series of experiments are conducted to obtain industrial data from an apparel manufacturer. The manufacturer needs to purchase a specified amount of raw fabric from 3 appropriate material suppliers for the production of its customers' orders. 
TABLE 2: The fuzzy evaluation of criteria of the overall objective.

\begin{tabular}{ccccccc}
\hline & $C_{1}$ & $C_{2}$ & $C_{3}$ & $C_{4}$ & $C_{5}$ & Weights \\
\hline$C_{1}$ & $(1,1,1)$ & $(2,3,4)$ & $(3,4,5)$ & $(5,6,7)$ & $(2,3,4)$ & 0.43 \\
$C_{2}$ & $(0.25,0.33,0.5)$ & $(1,1,1)$ & $(3,4,5)$ & $(2,3,4)$ & $(4,5,6)$ & 0.33 \\
$C_{3}$ & $(0.2,0.25,0.33)$ & $(0.2,0.25,0.33)$ & $(1,1,1)$ & $(3,4,5)$ & $(2,3,4)$ & 0.13 \\
$C_{4}$ & $(0.14,0.17,0.2)$ & $(0.25,0.33,0.5)$ & $(0.2,0.25,0.33)$ & $(1,1,1)$ & $(2,3,4)$ & 0.02 \\
$C_{5}$ & $(0.25,0.33,0.5)$ & $(0.17,0.2,0.25)$ & $(0.25,0.33,0.5)$ & $(0.25,0.33,0.5)$ & $(1,1,1)$ & 0.09 \\
\hline
\end{tabular}

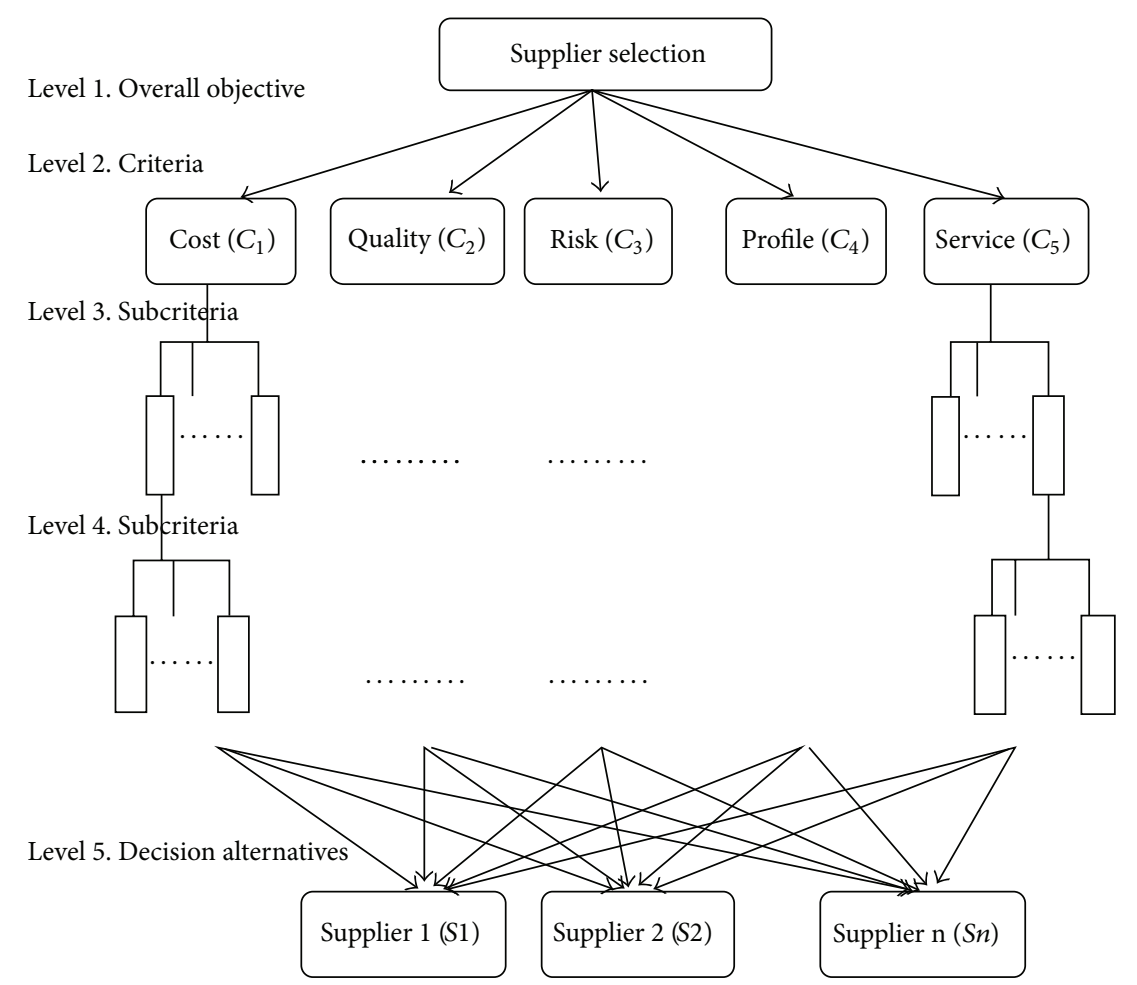

FIGURE 4: General hierarchy for supplier selection.

The 3 suppliers have been selected from its $N$ collaborative suppliers. The manufacturer seeks to determine how much should be purchased from the 3 key suppliers in order to minimize its overall cost and maximize its utility over a multiperiod planning horizon.

4.1. Experiment for FEAHP-Based Supplier Ranking. The FEAHP starts from the pairwise comparison matrices of five criteria (Table 2). Based on these matrices, the weights of suppliers and criteria are calculated and presented in Table 3. The supplier's information and manufacturer's demands are shown in Tables 4 and 5, respectively. The solutions to single objectives are shown in Table 6, where cost is minimum. Table 7 shows the order allocation based on minimum risk.

This paper presents the results of 6 experiments.

The criteria for selection of global suppliers are as follows:

(i) overall cost of products $\left(C_{1}\right)$ : product price $\left(A_{1}\right)$, freight cost $\left(A_{2}\right)$, penalty for delayed payment $\left(A_{3}\right)$, and tariff and custom duties $\left(A_{4}\right)$; (ii) product quality $\left(C_{2}\right)$ : rejection rate $\left(A_{5}\right)$, response to changes $\left(A_{6}\right)$, and rate of warranty claims $\left(A_{7}\right)$;

(iii) risk factors $\left(C_{3}\right)$ : lead time $\left(A_{8}\right)$, political stability $\left(A_{9}\right)$, geographical location $\left(A_{10}\right)$, and inability to meet further requirements $\left(A_{11}\right)$;

(iv) supplier's profile $\left(C_{4}\right)$ : financial status $\left(A_{12}\right)$, performance history $\left(A_{13}\right)$, and production capacity $\left(A_{14}\right)$;

(v) service performance of suppliers $\left(C_{5}\right)$ : remedy for quality problems $\left(A_{15}\right)$ and delivery schedule $\left(A_{16}\right)$.

These criteria can be found in the hierarchical structure shown in Figure 5.

4.1.1. Determination of Criteria and Subcriteria Weights. The example of the pairwise comparison matrices shows that the fifth row and column attach importance to the row's criterion relative to the column's criterion (Table 2 ).

Due to a good cost performance, the criterion for the first row is slightly preferred to the one on product quality, risk 


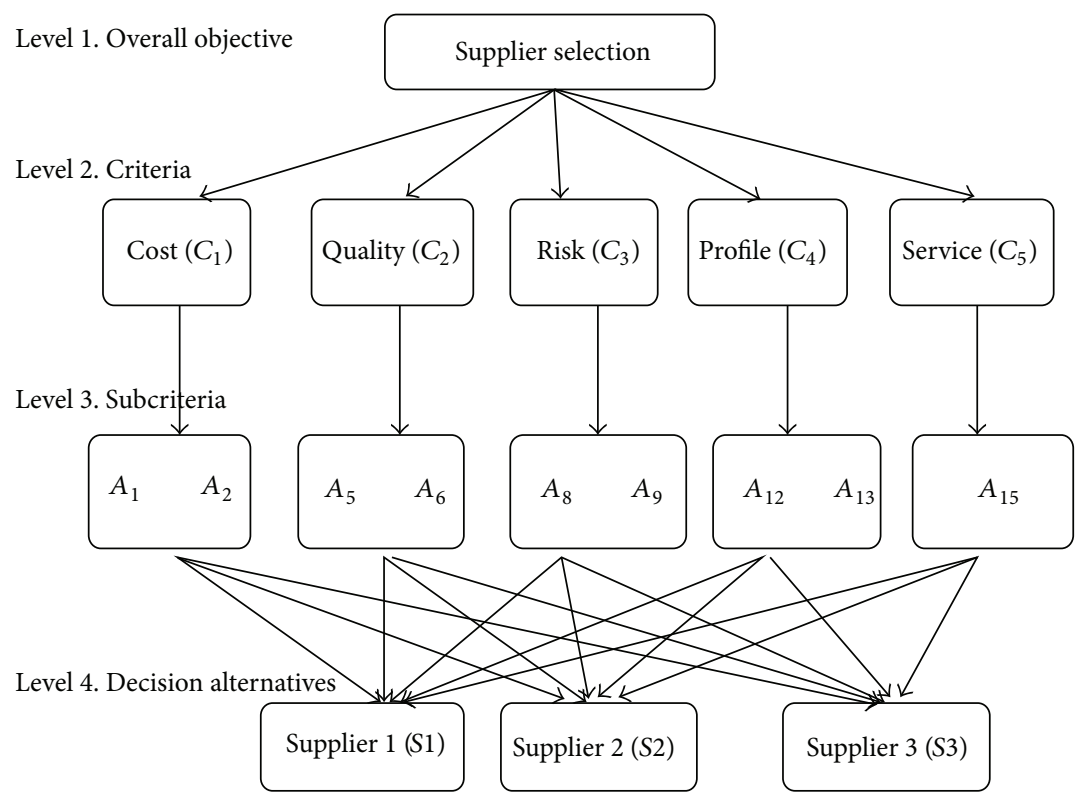

FIGURE 5: Hierarchy for supplier selection.

TABLE 3: The fuzzy evaluation of the attributes of criterion $C_{1}$.

\begin{tabular}{|c|c|c|c|c|c|}
\hline & $A_{1}$ & $A_{2}$ & $A_{3}$ & $A_{4}$ & Weights \\
\hline$A_{1}$ & $(1,1,1)$ & $(2,3,4)$ & $(3,4,5)$ & $(3,4,5)$ & 0.49 \\
\hline$A_{2}$ & $(0.25,0.33,0.5)$ & $(1,1,1)$ & $(3,4,5)$ & $(2,3,4)$ & 0.31 \\
\hline$A_{3}$ & $(0.2,0.25,0.33)$ & $(0.2,0.25,0.33)$ & $(1,1,1)$ & $(3,4,5)$ & 0.09 \\
\hline$A_{4}$ & $(0.2,0.25,0.33)$ & $(0.25,0.33,0.5)$ & $(0.2,0.25,0.33)$ & $(1,1,1)$ & 0.11 \\
\hline
\end{tabular}

TABLE 4: The fuzzy evaluation of the attributes of criterion $C_{2}$.

\begin{tabular}{ccccc}
\hline & $A_{5}$ & $A_{6}$ & $A_{7}$ & Weights \\
\hline$A_{5}$ & $(1,1,1)$ & $(4,5,6)$ & $(2,3,4)$ & 0.55 \\
$A_{6}$ & $(0.17,0.2,0.25)$ & $(1,1,1)$ & $(3,4,5)$ & 0.19 \\
$A_{7}$ & $(0.25,0.33,0.5)$ & $(0.2,0.25,0.33)$ & $(1,1,1)$ & 0.26 \\
\hline
\end{tabular}

factors, and service performance of suppliers (the fuzzy values of $(2,3,4),(3,4,5)$, and $(2,3,4)$, resp.), which is strongly preferred to the supplier's profile (the value of $(5,6,7)$ ). Due to a good quality performance, the criterion for the second row and column is moderately more important than the service performance of suppliers (the value of $(4,5,6)$ ). Having fewer risk factors, the third row's criterion is slightly preferred to a good profile (value of $(3,4,5))$. Decision makers only need to fill in the upper half of the comparison matrix by assuming that the pairwise comparison of cost and service performance is $(2,3,4)$, following the pairwise comparison of service performance and cost $(0.25,0.33,0.5)$. The value of $(1,1,1)$ is assigned to diagonal elements.

Calculate various decision alternatives of fuzzy numbers based on Section 3 as follows:

$$
\begin{aligned}
S_{\mathcal{C}_{1}} & =(13,17,21) \times\left(\frac{1}{56.95}, \frac{1}{45.78}, \frac{1}{35.16}\right) \\
& =(0.23,0.37,0.60),
\end{aligned}
$$

$$
\begin{aligned}
S_{c_{2}} & =(10.25,13.33,16.5) \times\left(\frac{1}{56.95}, \frac{1}{45.78}, \frac{1}{35.16}\right) \\
& =(0.18,0.29,0.47) \\
S_{c_{3}} & =(6.40,8.50,10.67) \times\left(\frac{1}{56.95}, \frac{1}{45.78}, \frac{1}{35.16}\right) \\
& =(0.11,0.19,0.30), \\
S_{c_{4}} & =(3.59,4.75,6.03) \times\left(\frac{1}{56.95}, \frac{1}{45.78}, \frac{1}{35.16}\right) \\
& =(0.06,0.10,0.17), \\
S_{c_{5}} & =(1.92,2.20,2.75) \times\left(\frac{1}{56.95}, \frac{1}{45.78}, \frac{1}{35.16}\right) \\
& =(0.03,0.05,0.08) .
\end{aligned}
$$

Compare the following decision alternatives:

$$
\begin{array}{cc}
V\left(S_{c_{1}} \geq S_{c_{2}}\right)=1, & V\left(S_{c_{1}} \geq S_{c_{3}}\right)=1, \\
V\left(S_{c_{1}} \geq S_{c_{4}}\right)=1, & V\left(S_{c_{1}} \geq S_{c_{5}}\right)=1, \\
V\left(S_{c_{2}} \geq S_{c_{1}}\right)=0.75, & V\left(S_{c_{2}} \geq S_{c_{3}}\right)=1,
\end{array}
$$


TABle 5: The fuzzy evaluation of the attributes of criterion $C_{3}$.

\begin{tabular}{lccccc}
\hline & $A_{8}$ & $A_{9}$ & $A_{10}$ & $A_{11}$ & Weights \\
\hline$A_{8}$ & $(1,1,1)$ & $(4,5,6)$ & $(4,5,6)$ & $(1,1,2)$ & 0.59 \\
$A_{9}$ & $(0.17,0.2,0.25)$ & $(1,1,1)$ & $(4,5,6)$ & $(2,3,4)$ & $(3,4,5)$ \\
$A_{10}$ & $(0.17,0.2,0.25)$ & $(0.17,0.2,0.25)$ & $(1,1,1)$ & $(1,1,1)$ & 0.39 \\
$A_{11}$ & $(0.5,1,1)$ & $(0.25,0.33,0.5)$ & $(0.2,0.25,0.33)$ & 0.01 \\
\hline
\end{tabular}

TABLE 6: The fuzzy evaluation of the attributes of criterion $C_{4}$.

\begin{tabular}{ccccc}
\hline & $A_{12}$ & $A_{13}$ & $A_{14}$ & Weights \\
\hline$A_{12}$ & $(1,1,1)$ & $(3,4,5)$ & $(3,4,5)$ & 0.51 \\
$A_{13}$ & $(0.2,0.25,0.33)$ & $(1,1,1)$ & $(3,4,5)$ & 0.18 \\
$A_{14}$ & $(0.2,0.25,0.33)$ & $(0.2,0.25,0.33)$ & $(1,1,1)$ & 0.31 \\
\hline
\end{tabular}

TABLE 7: The fuzzy evaluation of the attributes of criterion $C_{5}$.

\begin{tabular}{cccc}
\hline & $A_{15}$ & $A_{16}$ & Weights \\
\hline$A_{15}$ & $(1,1,1)$ & $(3,4,5)$ & 0.52 \\
$A_{16}$ & $(0.2,0.25,0.33)$ & $(1,1,1)$ & 0.48 \\
\hline
\end{tabular}

$$
\begin{array}{cc}
V\left(S_{c_{2}} \geq S_{c_{4}}\right)=1, & V\left(S_{c_{2}} \geq S_{c_{5}}\right)=1, \\
V\left(S_{c_{3}} \geq S_{c_{1}}\right)=0.29, & V\left(S_{c_{3}} \geq S_{c_{2}}\right)=0.54, \\
V\left(S_{c_{3}} \geq S_{c_{4}}\right)=1, & V\left(S_{c_{3}} \geq S_{c_{5}}\right)=1, \\
V\left(S_{c_{4}} \geq S_{c_{1}}\right)=0.27, & V\left(S_{c_{4}} \geq S_{c_{2}}\right)=0.05, \\
V\left(S_{c_{4}} \geq S_{c_{3}}\right)=0.42, & V\left(S_{c_{4}} \geq S_{c_{5}}\right)=1, \\
V\left(S_{c_{5}} \geq S_{c_{1}}\right)=0.87, & V\left(S_{c_{5}} \geq S_{c_{2}}\right)=0.72, \\
V\left(S_{c_{5}} \geq S_{c_{3}}\right)=0.33, & V\left(S_{c_{5}} \geq S_{c_{4}}\right)=0.21 .
\end{array}
$$

Calculate the following decision alternatives' weights:

$$
\begin{gathered}
d^{\prime}\left(c_{1}\right)=\min (1,1,1,1)=1, \\
d^{\prime}\left(c_{2}\right)=\min (0.75,1,1,1)=0.75, \\
d^{\prime}\left(c_{3}\right)=\min (0.29,0.54,1,1)=0.29, \\
d^{\prime}\left(c_{4}\right)=\min (0.27,0.05,0.42,1)=0.05, \\
d^{\prime}\left(c_{5}\right)=\min (0.87,0.72,0.33,0.21)=0.21 .
\end{gathered}
$$

Priority weights form $W^{\prime}=(1,0.75,0.29,0.05,0.21)$ vector. Normalizing the $W^{\prime}$ vector:

$$
\begin{aligned}
& w_{1}=\frac{1}{1+0.75+0.29+0.05+0.21}=0.43 \\
& w_{2}=\frac{0.75}{1+0.75+0.29+0.05+0.21}=0.33
\end{aligned}
$$

$$
\begin{aligned}
& w_{3}=\frac{0.29}{1+0.75+0.29+0.05+0.21}=0.13 \\
& w_{4}=\frac{0.05}{1+0.75+0.29+0.05+0.21}=0.02 \\
& w_{5}=\frac{0.21}{1+0.75+0.29+0.05+0.21}=0.09
\end{aligned}
$$

After normalization of the values, priority weights of the main goal are calculated as $(0.43,0.33,0.13,0.02,0.09)$. The results (principal vectors) show that the criteria have the following approximate priority weights: cost (0.43), quality (0.33), risk (0.13), supplier's profile (0.02) and service performance of suppliers (0.09).

Different attributes are compared by each criterion separately with the same procedure as discussed above. The fuzzy evaluation matrices of attributes and the weight vectors of subcriteria are shown in Tables 3, 4, 5, 6, and 7.

4.1.2. Calculate the Suppliers' Weights. Similarly, the fuzzy evaluation matrices of decision alternatives and the corresponding weight vector of each alternative with respect to the corresponding attributes are determined. The priority weights of suppliers with respect to each criterion are given by adding each supplier's weight to each corresponding attribute's weight. The results are shown in Tables 8, 9, 10, 11, and 12.

Finally, the priority weight of each supplier can be calculated by multiplying the weight of each corresponding criterion. The results are shown in Table 13. The summary of the overall attributes is shown in Table 13. It should be noted that among the three given suppliers, " $S 1$ " has the highest weight and therefore is selected as the best supplier to satisfy the goals and objectives of the manufacturing company. Table 13 also shows the final score of each supplier s' results and rankings. As can be seen, $S 1$ (0.5) scores higher than $S 2(0.23)$ and $S 3$ (0.23). The important results are shown in Figures 6 and 7.

4.2. Experiment for Dynamic Order Allocation. A real apparel manufacturer purchasing environment usually has the following four scenarios. (1) A manufacturer's demand for common material is the same in all planning periods; in order to obtain orders steadily, suppliers reserve a certain capacity and offer a reasonable price. (2) Demands for common material are steady, but suppliers do not reserve a certain capacity; so, price and capacity fluctuate in different planning periods. (3) Suppliers' prices are different throughout the planning 
TABLE 8: The fuzzy evaluation of the subcriteria of criterion $C_{1}$.

\begin{tabular}{lccccc}
\hline & $A_{1}$ & $A_{2}$ & $A_{3}$ & $A_{4}$ & Alternative priority \\
Weight & 0.49 & 0.31 & 0.09 & 0.11 & \\
Alternatives & & & & 0.87 & 0.57 \\
$S 1$ & 0.51 & 0.51 & 0.69 & 0.01 & 0.19 \\
$S 2$ & 0.23 & 0.23 & 0.08 & 0.12 & 0.24 \\
$S 3$ & 0.26 & 0.26 & 0.23 & & \\
\hline
\end{tabular}

TABLE 9: The fuzzy evaluation of the subcriteria of criterion $C_{2}$.

\begin{tabular}{lcccc}
\hline & $A_{5}$ & $A_{6}$ & $A_{7}$ & $\begin{array}{c}\text { Alternative priority } \\
\text { Weight }\end{array}$ \\
\hline Alternatives & 0.55 & 0.19 & 0.26 & weight \\
$\quad$ S1 & 0.42 & 0.49 & 0.53 & 0.46 \\
S2 & 0.28 & 0.23 & 0.15 & 0.24 \\
S3 & 0.30 & 0.28 & 0.32 & 0.30 \\
\hline
\end{tabular}

TABLE 10: The fuzzy evaluation of the subcriteria of criterion $C_{3}$.

\begin{tabular}{lccccc}
\hline & $A_{8}$ & $A_{9}$ & $A_{10}$ & $A_{11}$ & $\begin{array}{c}\text { Alternative priority } \\
\text { weight }\end{array}$ \\
\hline Weight & 0.59 & 0.39 & 0.01 & 0.01 & \\
Alternatives & & & & & \\
S1 & 0.51 & 0.53 & 0.69 & 0.68 & 0.52 \\
S2 & 0.21 & 0.23 & 0.08 & 0.11 & 0.22 \\
S3 & 0.28 & 0.24 & 0.23 & 0.21 & 0.26 \\
\hline
\end{tabular}

TABLE 11: The fuzzy evaluation of the subcriteria of criterion $C_{4}$.

\begin{tabular}{lcccc}
\hline & $A_{12}$ & $A_{13}$ & $A_{14}$ & $\begin{array}{c}\text { Alternative priority } \\
\text { Weight }\end{array}$ \\
\hline Weight & 0.51 & 0.18 & 0.31 & \\
Alternatives & & & & \\
S1 & 0.39 & 0.49 & 0.51 & 0.45 \\
S2 & 0.28 & 0.21 & 0.17 & 0.23 \\
S3 & 0.33 & 0.30 & 0.32 & 0.32 \\
\hline
\end{tabular}

TABle 12: The fuzzy evaluation of the subcriteria of criterion $C_{5}$.

\begin{tabular}{lccc}
\hline & $A_{15}$ & $A_{16}$ & $\begin{array}{c}\text { Alternative priority } \\
\text { weight }\end{array}$ \\
\hline Alternatives & 0.52 & 0.48 & \\
S1 & & & 0.37 \\
S2 & 0.39 & 0.35 & 0.37 \\
S3 & 0.33 & 0.41 & 0.26 \\
\hline
\end{tabular}

period. (4) Suppliers' capacities and prices are different throughout the planning periods.

4.2.1. Scenario 1: Suppliers Can Reserve a Certain Capacity and Offer a Reasonable Price in All Planning Periods. After getting the weight score of each supplier and criterion in the first stage, $w_{c_{1}}=0.43$ and $w_{c_{2}}=0.13$. In addition to having the capacity and price information on each supplier, the

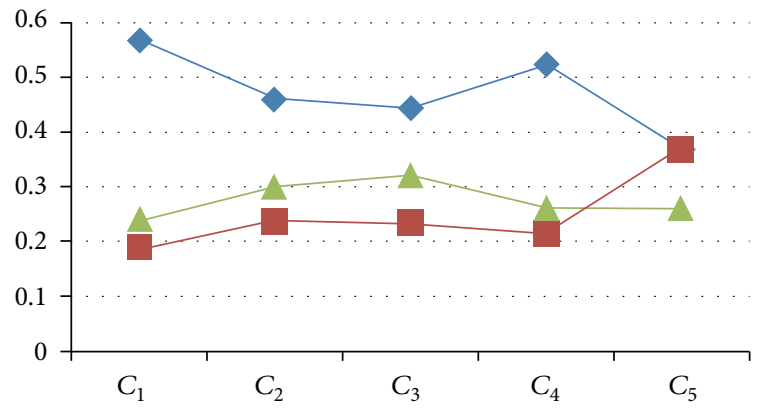

$-S 1$
$-S 2$
$-S 3$

FIgURE 6: The suppliers based on the criteria.

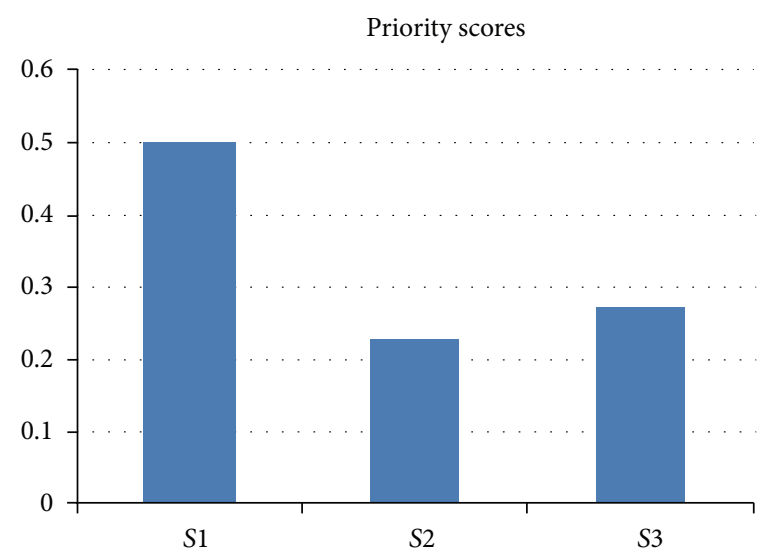

Priority scores

FIGURE 7: Final priority weights of the suppliers.

dynamic approach mentioned in Section 3.2 can be rewritten as follows:

$$
\begin{array}{r}
V_{2, t}=\min _{0 \leq x_{i t} \leq c_{i t}}\left\{0.43 \sum_{i=1}^{n} p_{i t} x_{i t}+0.13 \sum_{i=1}^{n} \frac{x_{i t}}{w_{i}}\right. \\
\left.+V_{2, t+1}\left(D_{t}-\sum_{i=1}^{n} x_{i t}\right)\right\} .
\end{array}
$$

If the manufacturer entirely just focuses on minimizing cost alone, the risk will increase substantially by $215 \%$ 
TABLE 13: Demand information.

\begin{tabular}{llll}
\hline Period & 1 & 2 & 3 \\
\hline Demand & 6 & 6 & 6 \\
\hline
\end{tabular}

TABLE 14: Price and capacity information.

\begin{tabular}{|c|c|c|c|c|}
\hline \multirow{2}{*}{ Supplier } & \multicolumn{3}{|c|}{ Ordering price (per unit) } & \multirow{2}{*}{ Capacity } \\
\hline & Period 1 & Period 2 & Period 3 & \\
\hline$S 1$ & 12 & 12 & 12 & 6 \\
\hline$S 2$ & 10 & 10 & 10 & 6 \\
\hline$S 3$ & 11 & 11 & 11 & 6 \\
\hline
\end{tabular}

TABLE 15: Optimal order quantities with respect to minimum risk.

\begin{tabular}{llllcc}
\hline Period & 1 & 2 & 3 & Total risk & Total cost \\
\hline$S 1$ & 6 & 6 & 6 & 30 & 216 \\
S2 & & & & & \\
S3 & & & & & \\
\hline
\end{tabular}

TABLE 16: Optimal order quantities with respect to minimum cost.

\begin{tabular}{llllcc}
\hline Period & 1 & 2 & 3 & Total risk & Total cost \\
\hline$S 1$ & & & & 94.7 & 180 \\
S2 & 6 & 6 & 6 & & \\
S3 & & & & & \\
\hline
\end{tabular}

TABLE 17: Optimal order quantity with respect to minimum cost and risk.

\begin{tabular}{llllcc}
\hline Period & 1 & 2 & 3 & Total risk & Total cost \\
\hline$S 1$ & 4 & 3 & 2 & 58 & 205 \\
$S 2$ & 1 & & 1 & & \\
$S 3$ & 1 & 3 & 3 & & \\
\hline
\end{tabular}

than entirely focusing on minimizing risk. On the opposite extreme, if the manufacturer just entirely focuses on minimizing risk, this would raise its cost by $20 \%$ than just entirely focuses on minimizing cost only.

By applying the bi-objective dynamic function, the tradeoff solution incurs at $13.9 \%$ and $94 \%$ higher than the objective of minimizing cost and minimizing risk respectively. These experimental results show that the proposed dynamic programming approach can generate a better trade-off solution than entirely focusing on minimizing cost and minimizing risk alone. (Tables 13, 14, 15, 16, and 17).

\subsubsection{Scenario 2: Suppliers Have Different Capacities and Offer} Different Prices in Different Planning Periods. After getting the weight score of each supplier and criterion in the first stage, $w_{c_{1}}=0.43$ and $w_{\mathcal{c}_{2}}=0.13$. In addition to having the capacity and price information on each supplier, the
TABLE 18: Demand information.

\begin{tabular}{llll}
\hline Period & 1 & 2 & 3 \\
\hline Demand & 6 & 6 & 6 \\
\hline
\end{tabular}

TABLE 19: Price and capacity information.

\begin{tabular}{|c|c|c|c|c|}
\hline \multirow{2}{*}{ Supplier } & \multicolumn{3}{|c|}{ Ordering price (per unit) } & \multirow{2}{*}{ Capacity } \\
\hline & Period 1 & Period 2 & Period 3 & \\
\hline$S 1$ & 12 & 11 & 14 & 5 \\
\hline$S 2$ & 11 & 12 & 10 & 6 \\
\hline S3 & 9 & 11 & 10 & 4 \\
\hline
\end{tabular}

TABLE 20: Optimal order quantities with respect to minimum risk.

\begin{tabular}{llllcc}
\hline Period & 1 & 2 & 3 & Total risk & Total cost \\
\hline$S 1$ & 6 & 6 & 6 & 30 & 222 \\
$S 2$ & & & & & \\
$S 3$ & & & & & \\
\hline
\end{tabular}

TABLE 21: Optimal order quantities with respect to minimum cost.

\begin{tabular}{llllcc}
\hline Period & 1 & 2 & 3 & Total risk & Total cost \\
\hline$S 1$ & & 5 & & 72.24 & 184 \\
$S 2$ & 2 & & 2 & & \\
$S 3$ & 4 & 1 & 4 & & \\
\hline
\end{tabular}

dynamic approach mentioned in Section 3.2 can be rewritten as follows:

$$
\begin{aligned}
V_{2, t}=\min _{0 \leq x_{i t} \leq c_{i t}}\{ & 0.43 \sum_{i=1}^{n} p_{i t} x_{i t}+0.13 \sum_{i=1}^{n} \frac{x_{i t}}{w_{i}} \\
& \left.+V_{2, t+1}\left(D_{t}-\sum_{i=1}^{n} x_{i t}\right)\right\} .
\end{aligned}
$$

If the manufacturer entirely just focuses on minimizing cost alone, the risk will increase substantially by $141 \%$ than entirely focusing on minimizing risk. On the opposite extreme, if the manufacturer just entirely focuses on minimizing risk, this would raise its cost by $20.7 \%$ than just entirely focuses on minimizing cost only.

By applying the bi-objective dynamic function, the tradeoff solution incurs at $9.2 \%$ and $77 \%$ higher than the objective of minimizing cost and minimizing risk respectively. These experimental results show that the proposed dynamic programming approach can generate a better trade-off solution than entirely focusing on minimizing cost and minimizing risk alone. (Tables 18, 19, 20, 21, and 22).

If the manufacturer entirely just focuses on minimizing cost alone, the risk will increase substantially by $61.1 \%$ than entirely focusing on minimizing risk. On the opposite extreme, if the manufacturer just entirely focuses on minimizing risk, this would raise its cost by $12.2 \%$ than just entirely focuses on minimizing cost only.

By applying the bi-objective dynamic function, the tradeoff solution incurs at $4.1 \%$ and $17.8 \%$ higher than the objective of minimizing cost and minimizing risk respectively. These 
TABLE 22: Optimal order quantity with respect to minimum cost and risk.

\begin{tabular}{llllcc}
\hline Period & 1 & 2 & 3 & Total risk & Total cost \\
\hline S1 & 3 & 5 & 3 & 53.1 & 201 \\
S2 & & & 3 & & \\
S3 & 3 & 1 & & & \\
\hline
\end{tabular}

TABLE 23: Demand information.

\begin{tabular}{lllll}
\hline Period & 1 & 2 & 3 & 4 \\
\hline Demand & 6 & 6 & 6 & 6 \\
\hline
\end{tabular}

TABLE 24: Price and capacity information.

\begin{tabular}{|c|c|c|c|c|c|}
\hline \multirow{2}{*}{$\begin{array}{l}\text { Supplier } \\
\text { period }\end{array}$} & \multicolumn{4}{|c|}{ Ordering price (per unit) } & \multirow{2}{*}{ Capacity } \\
\hline & 1 & 2 & 3 & 4 & \\
\hline$S 1$ & 12 & 11 & 14 & 10 & 5 \\
\hline$S 2$ & 11 & 12 & 10 & 11 & 6 \\
\hline$S 3$ & 9 & 11 & 10 & 11 & 4 \\
\hline
\end{tabular}

TABLE 25: Optimal order quantities with respect to minimum risk.

\begin{tabular}{lcccccc}
\hline Period & 1 & 2 & 3 & 4 & Total risk & Total cost \\
\hline$S 1$ & 5 & 5 & 5 & 5 & 54.76 & 276 \\
S2 & & & & & & \\
S3 & 1 & 1 & 1 & 1 & & \\
\hline
\end{tabular}

TABLE 26: Optimal order quantities with respect to minimum cost.

\begin{tabular}{lcccccc}
\hline Period & 1 & 2 & 3 & 4 & Total risk & Total cost \\
\hline$S 1$ & & 5 & & & 88.21 & 246 \\
$S 2$ & & & 6 & 6 & & \\
$S 3$ & 6 & 1 & & & & \\
\hline
\end{tabular}

TABLE 27: Optimal order quantity with respect to minimum cost and risk.

\begin{tabular}{lllllcc}
\hline Period & 1 & 2 & 3 & 4 & Total risk & Total cost \\
\hline S1 & 5 & 5 & & 5 & 64.48 & 256 \\
S2 & & & 2 & & & \\
S3 & 1 & 1 & 4 & 1 & & \\
\hline
\end{tabular}

experimental results show that the proposed dynamic programming approach can generate a better trade-off solution than entirely focusing on minimizing cost and minimizing risk alone. (Tables 23, 24, 25, 26, and 27).

4.2.3. Scenario 3: The Manufacturer's Demands and the Supplier's Prices Are Different throughout the Planning Periods. After getting the weight score of each supplier and criterion in the first stage, $w_{c_{1}}=0.43$ and $w_{c_{2}}=0.13$. In addition to having the capacity and price information on each supplier, the
TABLE 28: Demand information.

\begin{tabular}{lccc}
\hline Period & 1 & 2 & 3 \\
\hline Demand & 11 & 9 & 10 \\
\hline
\end{tabular}

TABLE 29: Price and capacity information.

\begin{tabular}{|c|c|c|c|c|}
\hline \multirow{2}{*}{ Supplier } & \multicolumn{3}{|c|}{ Ordering price (per unit) } & \multirow{2}{*}{ Capacity } \\
\hline & Period 1 & Period 2 & Period 3 & \\
\hline$S 1$ & 95 & 95 & 99 & 4 \\
\hline$S 2$ & 87 & 87 & 89 & 4 \\
\hline$S 3$ & 93 & 91 & 91 & 6 \\
\hline
\end{tabular}

TABLE 30: Optimal order quantities with respect to minimum risk.

\begin{tabular}{llllcc}
\hline Period & 1 & 2 & 3 & Total risk & Total cost \\
\hline S1 & 4 & 4 & 4 & 90.69 & 2802 \\
S2 & 1 & & & & \\
S3 & 6 & 5 & 6 & & \\
\hline
\end{tabular}

dynamic approach mentioned in Section 3.2 can be rewritten as follows:

$$
\begin{aligned}
V_{2, t}=\min _{0 \leq x_{i t} \leq c_{i t}}\{ & 0.43 \sum_{i=1}^{n} p_{i t} x_{i t}+0.13 \sum_{i=1}^{n} \frac{x_{i t}}{w_{i}} \\
& \left.+V_{2, t+1}\left(D_{t}-\sum_{i=1}^{n} x_{i t}\right)\right\} .
\end{aligned}
$$

If the manufacturer entirely just focuses on minimizing cost alone, the risk will increase substantially by $28 \%$ than entirely focusing on minimizing risk. On the opposite extreme, if the manufacturer just entirely focuses on minimizing risk, this would raise its cost by $4 \%$ than just entirely focuses on minimizing cost only.

By applying the bi-objective dynamic function, the tradeoff solution incurs at $1 \%$ and $16 \%$ higher than the objective of minimizing cost and minimizing risk respectively. These experimental results show that the proposed dynamic programming approach can generate a better trade-off solution than entirely focusing on minimizing cost and minimizing risk alone. (Tables 28, 29, 30, 31, and 32).

If the manufacturer entirely just focuses on minimizing cost alone, the risk will increase substantially by $32 \%$ than entirely focusing on minimizing risk. On the opposite extreme, if the manufacturer just entirely focuses on minimizing risk, this would raise its cost by $4 \%$ than just entirely focuses on minimizing cost only.

By applying the bi-objective dynamic function, the tradeoff solution incurs at $1 \%$ and $15.7 \%$ higher than the objective of minimizing cost and minimizing risk respectively. These experimental results show that the proposed dynamic programming approach can generate a better trade-off solution than entirely focusing on minimizing cost and minimizing risk alone. (Tables 33, 34, 35, 36, and 37).

4.2.4. Scenario 4: Demands, Price, and Capacity Are Different throughout the Planning Periods. After getting the weight 
TABLE 31: Optimal order quantities with respect to minimum cost.

\begin{tabular}{llllcc}
\hline Period & 1 & 2 & 3 & Total risk & Total cost \\
\hline$S 1$ & 1 & & & 116.8 & 2706 \\
$S 2$ & 4 & 4 & 4 & & \\
S3 & 6 & 5 & 6 & & \\
\hline
\end{tabular}

TABLE 32: Optimal order quantity with respect to minimum cost and risk.

\begin{tabular}{llllcc}
\hline Period & 1 & 2 & 3 & Total risk & Total cost \\
\hline S1 & 4 & 4 & 0 & 105.21 & 2728 \\
S2 & 4 & 4 & 4 & & \\
S3 & 3 & 1 & 6 & & \\
\hline
\end{tabular}

TABle 33: Demand information.

\begin{tabular}{lcccc}
\hline Period & 1 & 2 & 3 & 4 \\
\hline Demand & 11 & 9 & 10 & 12 \\
\hline
\end{tabular}

TABle 34: Price and capacity information.

\begin{tabular}{|c|c|c|c|c|c|}
\hline \multirow{2}{*}{$\begin{array}{l}\text { Supplier } \\
\text { period }\end{array}$} & \multicolumn{4}{|c|}{ Ordering price (per unit) } & \multirow{2}{*}{ Capacity } \\
\hline & 1 & 2 & 3 & 4 & \\
\hline$S 1$ & 95 & 95 & 99 & 96 & 5 \\
\hline$S 2$ & 87 & 87 & 89 & 90 & 4 \\
\hline$S 3$ & 93 & 91 & 91 & 93 & 6 \\
\hline
\end{tabular}

TABLE 35: Optimal order quantities with respect to minimum risk.

\begin{tabular}{lllllcc}
\hline Period & 1 & 2 & 3 & 4 & Total risk & Total cost \\
\hline$S 1$ & 5 & 5 & 5 & 5 & 121.38 & 3950 \\
$S 2$ & & & & 1 & & \\
S3 & 6 & 4 & 5 & 6 & & \\
\hline
\end{tabular}

TABLE 36: Optimal order quantities with respect to minimum cost.

\begin{tabular}{lllllcc}
\hline Period & 1 & 2 & 3 & 4 & Total risk & Total cost \\
\hline$S 1$ & 1 & & & 2 & 160.29 & 3816 \\
$S 2$ & 4 & 4 & 4 & 4 & & \\
S3 & 6 & 5 & 6 & 6 & & \\
\hline
\end{tabular}

TABLE 37: Optimal order quantity with respect to minimum cost and risk.

\begin{tabular}{lllllcc}
\hline Period & 1 & 2 & 3 & 4 & Total risk & Total cost \\
\hline$S 1$ & 5 & 5 & & 5 & 140.43 & 3853 \\
$S 2$ & 4 & 4 & 4 & 4 & & \\
S3 & 2 & & 6 & 3 & & \\
\hline
\end{tabular}

score of each supplier and criterion in the first stage, $w_{c_{1}}=$ 0.43 and $w_{\mathcal{c}_{2}}=0.13$. In addition to having the capacity and
TABLE 38: Demand information.

\begin{tabular}{lccc}
\hline Period & 1 & 2 & 3 \\
\hline Demand & 11 & 9 & 10 \\
\hline
\end{tabular}

TABLE 39: Price and capacity information.

\begin{tabular}{lcccccc}
\hline Supplier & \multicolumn{2}{c}{ Ordering price (per unit) } & \multicolumn{3}{c}{ Capacity } \\
period & 1 & 2 & 3 & 1 & 2 & 3 \\
\hline$S 1$ & 95 & 95 & 99 & 4 & 6 & 5 \\
$S 2$ & 87 & 87 & 89 & 4 & 7 & 7 \\
$S 3$ & 93 & 91 & 91 & 6 & 5 & 6 \\
\hline
\end{tabular}

TABLE 40: Optimal order quantities with respect to minimum risk.

\begin{tabular}{llllcc}
\hline Period & 1 & 2 & 3 & Total risk & Total cost \\
\hline$S 1$ & 4 & 6 & 5 & 85.7 & 2818 \\
S2 & 1 & & & & \\
S3 & 6 & 3 & 5 & & \\
\hline
\end{tabular}

price information on each supplier, the dynamic approach mentioned in Section 3.2 can be rewritten as follows:

$$
\begin{aligned}
V_{2, t}=\min _{0 \leq x_{i t} \leq c_{i t}}\{ & 0.43 \sum_{i=1}^{n} p_{i t} x_{i t}+0.13 \sum_{i=1}^{n} \frac{x_{i t}}{w_{i}} \\
& \left.+V_{2, t+1}\left(D_{t}-\sum_{i=1}^{n} x_{i t}\right)\right\} .
\end{aligned}
$$

If the manufacturer entirely just focuses on minimizing cost alone, the risk will increase substantially by $20 \%$ than entirely focusing on minimizing risk. On the opposite extreme, if the manufacturer just entirely focuses on minimizing risk, this would raise its cost by $5 \%$ than just entirely focuses on minimizing cost only.

By applying the bi-objective dynamic function, the tradeoff solution incurs at $1 \%$ and $9 \%$ higher than the objective of minimizing cost and minimizing risk respectively. These experimental results show that the proposed dynamic programming approach can generate a better trade-off solution than entirely focusing on minimizing cost and minimizing risk alone. (Tables 38, 39, 40, 41, and 42).

\section{Conclusions}

This paper investigates the topic of multiobjective order allocation based on supplier selection in the purchasing stage with single material and multiple suppliers taken into consideration. A mathematical model for investigation is established, which considers minimizing the total cost and risk in all purchasing processes. These objectives are particularly useful for manufacturing companies to survive in a make-toorder environment and improve the performance of supply chain management.

The SSOA model comprises two processes, namely, an FEAHP-based supplier/criteria ranking process and a DPbased order allocation process. In the FEAHP process, the weight of each criterion and supplier is obtained. Based 
TABLE 41: Optimal order quantities with respect to minimum cost.

\begin{tabular}{llllcc}
\hline Period & 1 & 2 & 3 & Total risk & Total cost \\
\hline$S 1$ & 1 & & & 103.5 & 2688 \\
$S 2$ & 4 & 7 & 7 & & \\
S3 & 6 & 2 & 3 & & \\
\hline
\end{tabular}

TABLE 42: Optimal order quantity with respect to minimum cost and risk.

\begin{tabular}{llllcc}
\hline Period & 1 & 2 & 3 & Total risk & Total cost \\
\hline$S 1$ & 4 & 2 & & 93.2 & 2708 \\
$S 2$ & 4 & 7 & 4 & & \\
S3 & 3 & & 6 & & \\
\hline
\end{tabular}

on their weights, the optimal order allocation solution is obtained using the DP technique.

The effectiveness of the proposed optimization model is validated by using real data from a manufacturing company. The experimental results show that the proposed model can handle order allocation effectively.

The proposed optimization model can handle order allocation based on supplier selection. Further research will consider the effects of various uncertainties on supply chain management, such as uncertain customers' orders and possible material shortages.

\section{Acknowledgment}

The authors would like to acknowledge the financial support of The Hong Kong Polytechnic University under the RPUG project.

\section{References}

[1] L. de Boer, E. Labro, and P. Morlacchi, "A review of methods supporting supplier selection," European Journal of Purchasing and Supply Management, vol. 7, no. 2, pp. 75-89, 2001.

[2] A. Aamodt and E. Plaza, "Case-based reasoning: foundational issues, methodological variations, and system approaches," $A I$ Communications, vol. 7, no. 1, pp. 39-59, 1994.

[3] Z. Degraeve, E. Labro, and F. Roodhooft, "Evaluation of vendor selection models from a total cost of ownership perspective," European Journal of Operational Research, vol. 125, no. 1, pp. 34$58,2000$.

[4] H. Deng, C. H. Yeh, and R. J. Willis, "Inter-company comparison using modified TOPSIS with objective weights," Computers and Operations Research, vol. 27, no. 10, pp. 963-973, 2000.

[5] T. L. Saaty, "How to make a decision: the analytic hierarchy process," European Journal of Operational Research, vol. 48, no. 1, pp. 9-26, 1990.

[6] R. E. Steuer and P. Na, "Multiple criteria decision making combined with finance: a categorized bibliographic study," European Journal of Operational Research, vol. 150, no. 3, pp. 496-515, 2003.

[7] B. Srdjevic and Z. Srdjevic, "Bi-criteria evolution strategy in estimating weights from the ahp ratio-scale matrices," Applied
Mathematics and Computation, vol. 218, no. 4, pp. 1254-1266, 2011.

[8] A. Ishizaka, D. Balkenborg, and T. Kaplan, "Does AHP help us make a choice? An experimental evaluation," Journal of the Operational Research Society, vol. 62, no. 10, pp. 1801-1812, 2011.

[9] P. J. M. van Laarhoven and W. Pedrycz, "A fuzzy extension of Saaty's priority theory," Fuzzy Sets and Systems, vol. 11, no. 1-3, pp. 229-241, 1983.

[10] J. J. Buckley, "Fuzzy hierarchical analysis," Fuzzy Sets and Systems, vol. 17, no. 3, pp. 233-247, 1985.

[11] F. T. S. Chan and N. Kumar, "Global supplier development considering risk factors using fuzzy extended AHP-based approach," Omega, vol. 35, no. 4, pp. 417-431, 2007.

[12] Y. M. Wang, Y. Luo, and Z. Hua, "On the extent analysis method for fuzzy AHP and its applications," European Journal of Operational Research, vol. 186, no. 2, pp. 735-747, 2008.

[13] M. Dagdeviren and I. Yuksel, "Developing a fuzzy analytic hierarchy process (ahp) model for behavior-based safety management," Information Sciences, vol. 178, no. 6, pp. 1717-1733, 2008.

[14] S. H. Ghodsypour and C. O’Brien, "A decision support system for supplier selection using an integrated analytic hierarchy process and linear programming," International Journal of Production Economics, vol. 56-57, pp. 199-212, 1998.

[15] H. Fazlollahtabar, I. Mahdavi, M. T. Ashoori, S. Kaviani, and N. Mahdavi-Amiri, "A multi-objective decision-making process of supplier selection and order allocation for multi-period scheduling in an electronic market," International Journal of Advanced Manufacturing Technology, vol. 52, no. 9-12, pp. 10391052, 2011.

[16] Y. Tang, Z. Wang, and J. A. Fang, "Controller design for synchronization of an array of delayed neural networks using a controllable probabilistic PSO," Information Sciences, vol. 181, no. 20, pp. 4715-4732, 2011.

[17] S. H. Ghodsypour and C. O'Brien, "The total cost of logistics in supplier selection, under conditions of multiple sourcing, multiple criteria and capacity constraint," International Journal of Production Economics, vol. 73, no. 1, pp. 15-27, 2001.

[18] Z. Guo, W. Wong, S. Leung, and M. Li, "Applications of artificial intelligence in the apparel industry: a review," Textile Research Journal, vol. 81, no. 18, pp. 1871-1892, 2011.

[19] Y. Tang, H. Gao, J. Kurths, and J. Fang, "Evolutionary pinning control and its application in uav coordination," IEEE Transactions on Industrial Informatics, vol. 8, no. 4, pp. 828-838, 2012.

[20] Y. Tang, Z. Wang, W. Wong, J. Kurths, and J. Fang, "Feedback learning particle swarm optimization," Applied Soft Computing, vol. 11, no. 8, pp. 4713-4725, 2011.

[21] W. Zhu, Y. Tang, J. Fang, and W. Zhang, "Adaptive population tuning scheme for differential evolution," Information Sciences, vol. 223, pp. 164-191, 2013.

[22] W. Zhu, J. Fang, Y. Tang, W. Zhang, and Y. Xu, "Identification of fractional-order systems via a switching differential evolution subject to noise perturbations," Physics Letters A, vol. 376, no. 45, pp. 3113-33120, 2012.

[23] W. Zhu, J. Fang, Y. Tang, W. Zhang, and W. Du, "Digital IIR filters design using differential evolution algorithm with a controllable probabilistic population size," PLoS One, vol. 7, Article ID e40549, 2012.

[24] E. A. Demirtas and Ö. Üstün, "An integrated multiobjective decision making process for supplier selection and order allocation," Omega, vol. 36, no. 1, pp. 76-90, 2008. 
[25] B. Soylu and S. Kapan Ulusoy, "A preference ordered classification for a multi-objective maxmin redundancy allocation problem," Computers and Operations Research, vol. 38, no. 12, pp. 1855-1866, 2011.

[26] Y. Tang, Z. Wang, W. K. Wong, J. Kurths, and J. Fang, "Multiobjective synchronization of coupled systems," Chaos, vol. 21, no. 2, article 025114, 2011.

[27] N. Xu and L. Nozick, "Modeling supplier selection and the use of option contracts for global supply chain design," Computers and Operations Research, vol. 36, no. 10, pp. 2786-2800, 2009.

[28] H. M. Wagner and T. M. Whitin, "Dynamic version of the economic lot size model," Management Science, vol. 5, pp. 89-96, 1958.

[29] C. Basnet and J. M. Y. Leung, "Inventory lot-sizing with supplier selection," Computers \& Operations Research, vol. 32, no. 1, pp. 1-14, 2005.

[30] B. Alidaee and G. A. Kochenberger, "A note on a simple dynamic programming approach to the single-sink, fixedcharge transportation problem," Transportation Science, vol. 39, no. 1, pp. 140-143, 2005.

[31] S. Li, A. Murat, and W. Huang, "Selection of contract suppliers under price and demand uncertainty in a dynamic market," European Journal of Operational Research, vol. 198, no. 3, pp. 830-847, 2009.

[32] T. Sawik, "Selection of a dynamic supply portfolio in maketo-order environment with risks," Computers \& Operations Research, vol. 38, no. 4, pp. 782-796, 2011.

[33] R. H. Lin, "An integrated FANP-MOLP for supplier evaluation and order allocation," Applied Mathematical Modelling, vol. 33, no. 6, pp. 2730-2736, 2009.

[34] F. Mafakheri, M. Breton, and A. Ghoniem, "Supplier selectionorder allocation: a two-stage multiple criteria dynamic programming approach," International Journal of Production Economics, vol. 132, no. 1, pp. 52-57, 2011.

[35] L. A. Zadeh, "Fuzzy sets," Information and Computation, vol. 8, pp. 338-353, 1965.

[36] N. K. Kasabov and Q. Song, "Denfis: dynamic evolving neuralfuzzy inference system and its application for time-series prediction," IEEE Transactions on Fuzzy Systems, vol. 10, no. 2, pp. 144-154, 2002. 


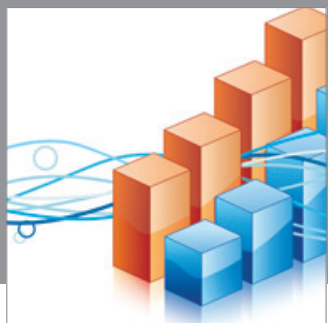

Advances in

Operations Research

mansans

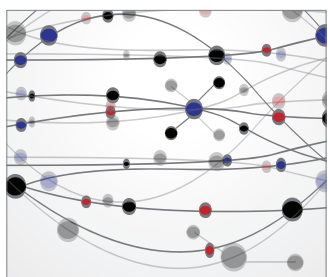

The Scientific World Journal
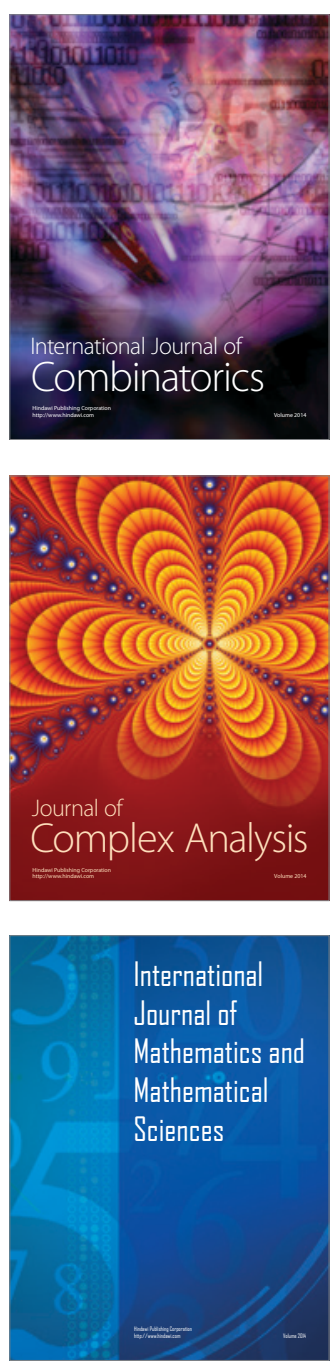
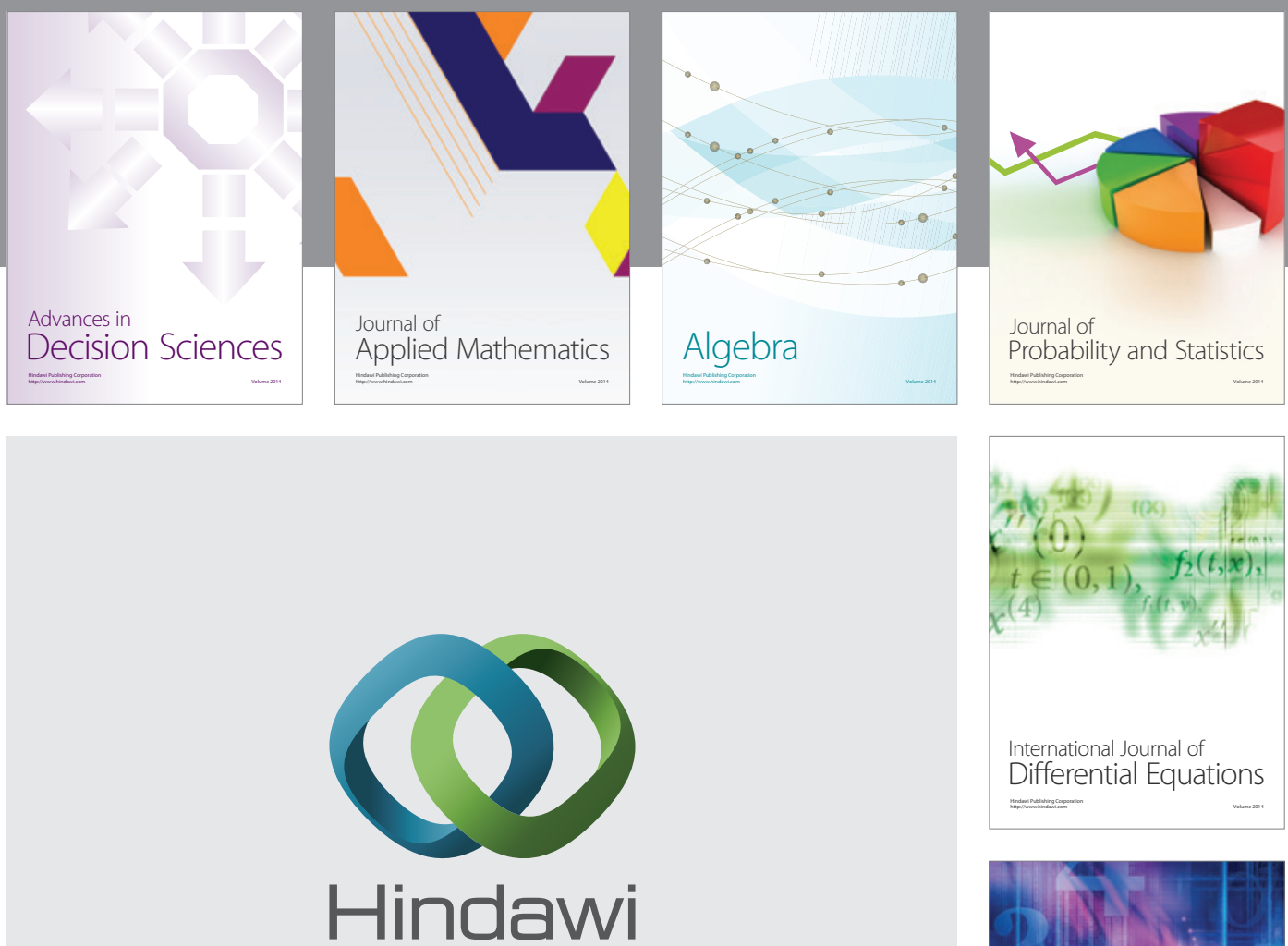

Submit your manuscripts at http://www.hindawi.com
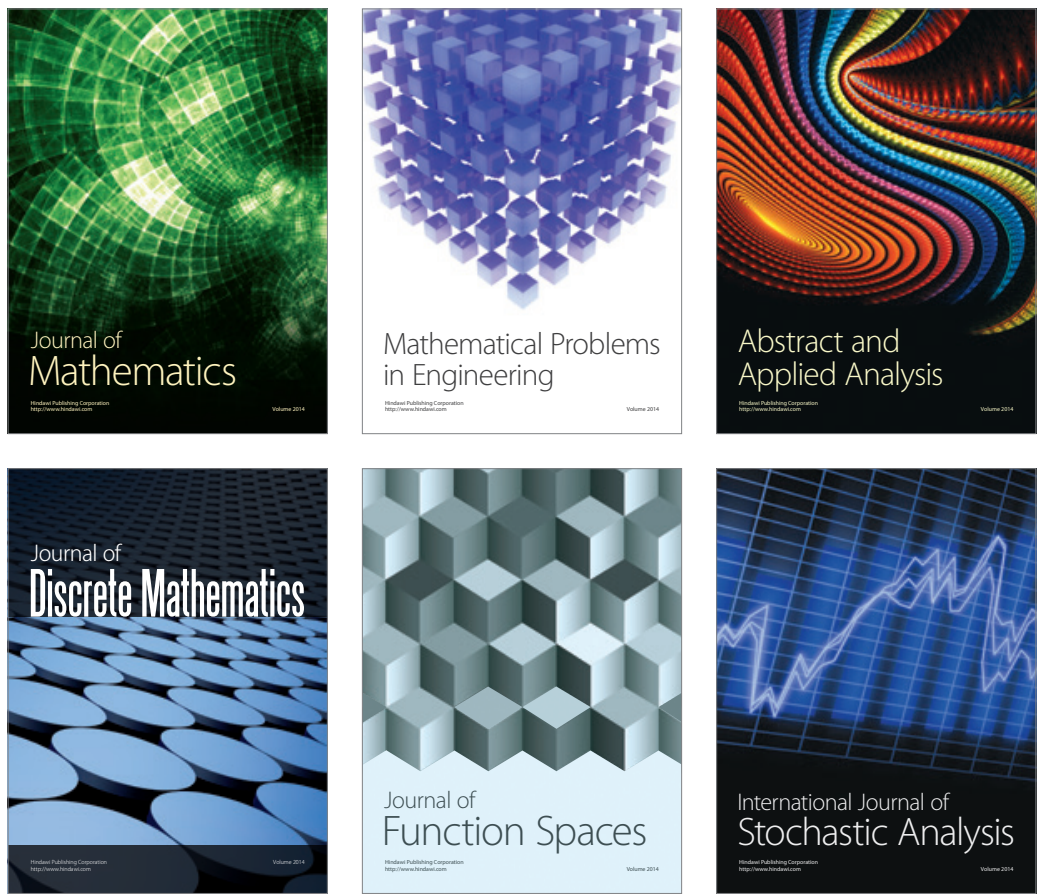

Journal of

Function Spaces

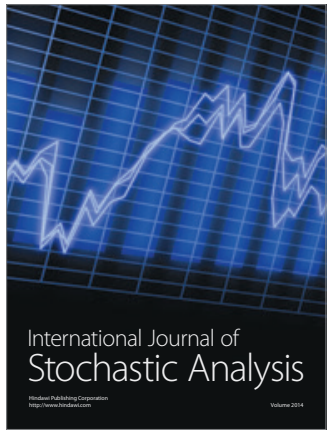

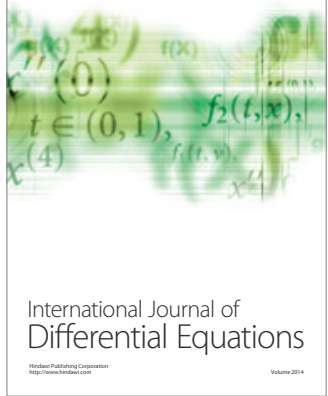
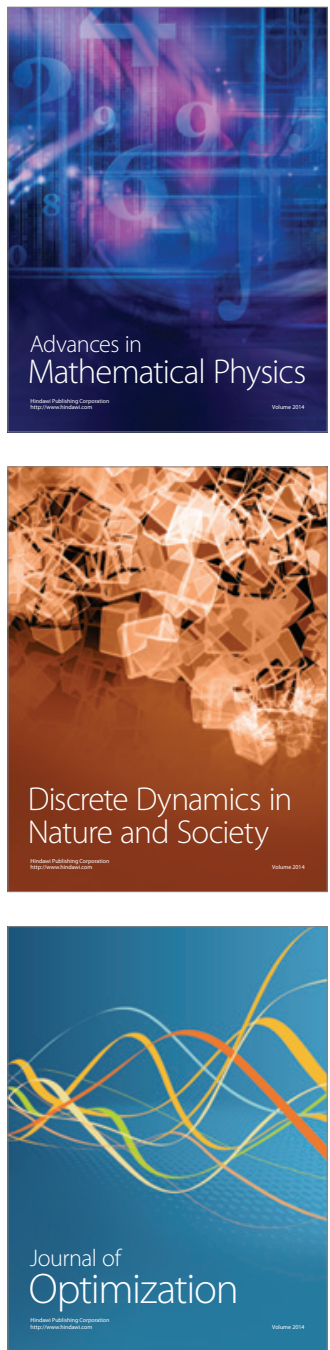